\title{
SORPTION OF PHENANTHRENE AND ATRAZINE BY PLANT CUTICULAR FRACTIONS
}

\author{
BENNY CHEFETZ* \\ Department of Soil and Water Sciences, Faculty of Agricultural, Food and Environmental Quality Sciences, \\ The Hebrew University of Jerusalem, P.O. Box 12, Rehovot 76100, Israel
}

(Received 1 October 2002; Accepted 26 February 2003)

\begin{abstract}
Several studies have shown selective preservation of plant cuticular materials in soils. However, very little is known about their function as sorbents for the hydrophobic organic contaminants (HOCs) in the soil. In this study, we investigated the sorption and desorption of phenanthrene and atrazine by cuticular fractions of pepper (bulk, dewaxed, nonsaponifiable, and nonhydrolyzable) to better understand the sorptive activity of cuticular matter in soils. The bulk and dewaxed cuticles exhibited carbonnormalized distribution coefficients $\left(K_{\mathrm{oc}}\right)$ for phenanthrene and atrazine in the range of that reported for soil humic substances, although both samples were rich in aliphatic structures. No hysteresis was observed in the desorption isotherms of either solute. The nonhydrolyzable residue exhibited a very high $K_{\text {oc }}$ value for atrazine, whereas the nonsaponifiable sample exhibited the lowest $K_{\text {oc }}$ value for both sorbates. Based on solubility parameter data, it is suggested that the nonsaponifiable sample be considered an intermediate between the physical and chemical mixture of pectin and cutan/lignin-like fractions, whereas the dewaxed cuticle is a chemical blending of cutin and pectin. The $n$-hexane-normalized sorption data suggest that the pepper cuticle can interact specifically with atrazine. This study leads to the conclusion that the contribution of aliphatic-rich plant biopolymers to the sorption of HOCs can be significant because of their preservation and accumulation in soils.
\end{abstract}

Keywords-Sorption Desorption Plant cuticle Cutin Cutan

\section{INTRODUCTION}

Sorption is a major process influencing the overall fate of hydrophobic organic contaminants (HOCs), such as polycyclic aromatic hydrocarbons (PAHs) and organochlorine pesticides, in the environment. Sorption has major effects on the physical accessibility of microorganisms to the pollutant and plays a significant role in pollutant sequestration. The predominant sorbent of HOCs is the soil or sedimentary organic matter (SOM). The content and chemical nature of SOM have been suggested as major factors controlling its sorption mechanism and affinity [1-5]. Most of these studies have suggested a positive correlation between the amount of HOC sorption and the level of aromatic carbon in the sample. Chiou et al. [3] suggested that the higher sorption of PAHs to aromatic rather than aliphatic components of SOM occurs in accordance with their higher solubility in aromatic versus aliphatic solvents. Ahmad et al. [6] reported a significant positive correlation between aromaticity of SOM and carbon-normalized distribution coefficient $\left(K_{\mathrm{oc}}\right)$ values of two hydrophobic pesticides. It was concluded that the aromatic content of SOM is a good predictor of the soil's ability to sorb nonionic pesticides. However, this theory failed to predict high sorption to a soil characterized by highly aliphatic SOM. It was therefore suggested that nonaromatic protein-like domains of SOM were initiating the sorption in that soil. In addition, Chefetz et al. [7] and Kopinke et al. [8] concluded that long aliphatic chains in cutin and aliphatic substituents of poly(acrylic acid) esters are more effective than aromatic moieties in binding pyrene, and Salloum et al. [9] suggested that aliphatic-rich SOM precursors can sorb a significant amount of phenanthrene.

The main sources of aliphatic compounds in soils are mi-

\footnotetext{
*chefetz@agri.huji.ac.il.
}

crobial lipids, plant waxes, and above- and below-ground plant biopolymers, such as cutin, cutan, and suberin [10,11]. Several studies have shown selective preservation of these aliphatic biopolymers in soils, with little or no alteration [12,13]. Nonhydrolyzable plant biopolymer (cutan) and root aliphatic biopolymer have been suggested to be responsible for the relative enrichment of forest soils in aliphatic components [14,15]. In addition, Augris et al. [16] and Rice [17] reported that nonhydrolyzable highly aliphatic organic components make up a significant fraction of the humin in soils, and Chefetz et al. [18] suggested that plant cuticular residues are an integral part of soil and peat humic acid macromolecules. Therefore, if we consider that plant cuticular material contributes significantly to SOM, we can hypothesize that those materials play an important role in the sorption of HOCs in soils because of their preservation and hydrophobic nature. The main objective of this research was to study the sorption and desorption processes of phenanthrene and atrazine to isolated plant cuticular fractions to better understand their sorptive activity in soils. Pepper cuticle was chosen as the model sorbent, consisting of both cutin and cutan polymers. Atrazine and phenanthrene were chosen as sorbates since they both have significant effects on the environment and the same molar volume but vary in structure, aqueous solubility, $\log K_{\mathrm{ow}}$, and their ability to form specific bonds with sorbents.

\section{MATERIALS AND METHODS}

Isolation and purification of pepper cuticular materials

Cuticle sheets were isolated from the fruits of green pepper (Capsicum annuum) using a modified version of the method reported by Kögel-Knabner et al. [19]. In brief, cuticle sheets were manually peeled from fresh fruits after boiling in water for $60 \mathrm{~min}$. Then the cuticle sheets were soaked in a solution 
Table 1. Relative yields, elemental analysis, and atomic ratios of the different pepper cuticle fractions

\begin{tabular}{|c|c|c|c|c|c|c|c|c|}
\hline Sample & & $\begin{array}{l}\text { Yield } \\
(\% \text { wt })\end{array}$ & $\mathrm{C}(\%)$ & $\mathrm{H}(\%)$ & N (\%) & $\mathrm{H} / \mathrm{C}$ & $\mathrm{O} / \mathrm{C}$ & $\mathrm{C} / \mathrm{N}$ \\
\hline Bulk cuticle & (PC1) & 100 & 59.16 & 8.23 & 1.31 & 1.67 & 0.40 & 52.71 \\
\hline Dewaxed cuticle & (PC2) & 96.4 & 59.13 & 7.84 & 1.34 & 1.59 & 0.40 & 51.54 \\
\hline Nonsaponifiable residue & (PC3) & 37.9 & 42.55 & 5.89 & 3.15 & 1.66 & 0.85 & 15.74 \\
\hline Nonhydrolyzable residue & (PC4) & 9.1 & 61.91 & 6.21 & 1.14 & 1.20 & 0.37 & 63.17 \\
\hline
\end{tabular}

of ammonium oxalate $(16 \mathrm{~g} / \mathrm{L})$ and oxalic acid $(4 \mathrm{~g} / \mathrm{L})$ at $90^{\circ} \mathrm{C}$ for $24 \mathrm{~h}$ and subjected to ultrasonic treatment in a water bath for $2 \mathrm{~h}$ to remove any residual fruit materials. This procedure yielded the bulk cuticle sheets (PC1). Waxy materials were removed from these sheets by Soxhlet extraction with chloroform/methanol (1:1) for $6 \mathrm{~h}$ to yield dewaxed cuticle (PC2). To remove cutin, the materials (PC2) were saponified with $1 \%$ potassium hydroxide in methanol for $3 \mathrm{~h}$ at $70^{\circ} \mathrm{C}$, yielding the nonsaponifiable fraction PC3. Carbohydrates were further removed from the PC3 fraction by acid hydrolysis $(6 \mathrm{M} \mathrm{HCl}$, reflex for $6 \mathrm{~h}$ ), resulting in the cutan residue (PC4). All samples were freeze-dried, ground, and sieved $(<0.5 \mathrm{~mm})$ before analysis and sorption experiments. The yields of the different treatments are presented in Table 1.

\section{Elemental and spectroscopic analyses}

Elemental $(\mathrm{C}, \mathrm{H}, \mathrm{N})$ analysis (Table 1) was conducted in duplicates using an automated elemental analyzer (EA 1108, Fisons Instruments, Milan, Italy). The cross-polarization (CP) magic angle spinning (MAS) ${ }^{13} \mathrm{C}$ nuclear magnetic resonance (NMR) spectra were acquired with a Bruker Avance $300 \mathrm{MHz}$ NMR spectrometer (Bruker Analytic, Billerica, MA, USA), equipped with a 4-mm H-X MAS probe, using the standard ramp-CP pulse program. The acquisition parameters were spectral frequency of $75 \mathrm{MHz}$ for ${ }^{13} \mathrm{C}$ and $300 \mathrm{MHz}$ for ${ }^{1} \mathrm{H}$, spinning rate of $13 \mathrm{kHz}$, ramp-CP contact time of $2 \mathrm{~ms}, 1-\mathrm{s}$ recycle delay, and line broadening of $50 \mathrm{~Hz}$. The spectra were divided into the following chemical shift regions: paraffinic carbons (0-50 ppm); alcohols, amines, carbohydrates, ethers, methoxyl, and acetal carbons (50-110 ppm); aromatic and phenolic carbons (110-165 ppm); and carboxyl and carbonyl carbons (165-215 ppm). The 0- to 110-ppm region was calculated as aliphatic $\mathrm{C}$ and the 110- to $165-\mathrm{ppm}$ region as aromatic $\mathrm{C}$. Total aromaticity was calculated by expressing aromatic $\mathrm{C}$ as percentage of the aliphatic plus aromatic $\mathrm{C}$, and total aliphaticity was calculated by expressing aliphatic $\mathrm{C}$ as percentage of the aliphatic and aromatic $\mathrm{C}$.

The Fourier transform infrared (FTIR) spectra of the samples were obtained for a wave number range of 4000 to 400 $\mathrm{cm}^{-1}$ on a Nicolet 550 Magna-IRTM spectrometer (Nicolet Instruments, Madison, WI, USA). Samples were oven-dried at $65^{\circ} \mathrm{C}$ for $48 \mathrm{~h}$ prior to analysis. Finely ground samples $(2 \mathrm{mg})$ were mixed with $98 \mathrm{mg}$ of $\mathrm{KBr}$ and compressed into pellets. To obtain FTIR spectra, 40 scans were collected; a linear baseline correction was applied using 4,000, 2,000, and $860 \mathrm{~cm}^{-1}$ as zero absorbance points.

\section{Batch sorption and desorption experiments}

Preliminary tests indicated apparent equilibrium of phenanthrene by $72 \mathrm{~h}$ of the batch sorption experiments. Aqueous solutions were prepared by adding of aliquots from concentrated methanol stocks of phenanthrene $(>98 \%$, Sigma, St. Louis, MO, USA) to deionized water solutions containing 5
$\mathrm{mM} \mathrm{CaCl}{ }_{2}$ as a mineral constituent, $100 \mathrm{mg} / \mathrm{L} \mathrm{NaN}_{3}$ to control biological activity, and $5 \mathrm{mg} / \mathrm{L} \mathrm{NaHCO}_{3}$ to buffer at $\mathrm{pH} 7$. Methanol concentration was maintained at less than $0.1 \%(\mathrm{v} /$ v) to avoid cosolvent effects. The sorbent mass (1-10 mg) was selected such that 30 to $70 \%$ of the sorbate would be sorbed at equilibrium.

Phenanthrene solutions $(200 \mathrm{ml})$ at various concentrations (0.1-1.0 mg/L) were added to pepper cuticular samples previously weighed into $250-\mathrm{ml}$ bottles (KG-35 borosilicate glass, Kimble/Kontes, Vineland, NJ, USA). The bottles (four replicates and a blank for each phenanthrene concentration) were sealed with aluminum foil and agitated in the dark at $200 \mathrm{rpm}$, $25^{\circ} \mathrm{C}$, for $72 \mathrm{~h}$. Then $1 \mathrm{ml}$ of the solution was filtered (glassfiber filter [GF/A]) for quantitative high-performance liquid chromatography (HPLC) analysis. Phenanthrene concentration was measured using an L-7100 LaChrom HPLC (Merck, Darmstadt, Germany) equipped with a photodiode array detector. Phenanthrene was determined using a LiChrospher ${ }^{\circledR}$ (Merck) PAH column $(25 \mathrm{~cm} \times 4 \mathrm{~mm}, 5 \mu \mathrm{m})$, a mobile phase of acetonitrile/water (80/20), and absorbance at a wavelength of $247 \mathrm{~nm}$.

Short-term batch sorption experiments with atrazine (2chloro-4-ethylamino-6-isopropylamino-s-triazine) were conducted for $48 \mathrm{~h}$ based on preliminary kinetics tests. Aliquots from a concentrated HPLC-grade methanol stock of atrazine (98.8\%, Agan Chemical, Ashdod, Israel) were dissolved in a solution containing $5 \mathrm{mM} \mathrm{CaCl}$ and $5 \mathrm{mg} / \mathrm{L} \mathrm{NaHCO}_{3}(\mathrm{pH} 7)$. Methanol concentration was maintained at less than $0.2 \%(\mathrm{v} /$ $\mathrm{v}$ ), and the mass of sorbent (10-90 mg) was selected to achieve 30 to $70 \%$ sorption. Atrazine solutions $(10 \mathrm{ml})$ at various concentrations $(1-20 \mathrm{mg} / \mathrm{L})$ were added to pepper cuticular samples previously weighed into $35-\mathrm{ml}$ Teflon ${ }^{\circledR}$ centrifuge tubes (Nalgene, Rochester, NY, USA). The tubes (four replicates and a blank for each atrazine concentration) were agitated in the dark at $200 \mathrm{rpm}, 25^{\circ} \mathrm{C}$, for $48 \mathrm{~h}$ and then centrifuged $(20,000 \mathrm{~g}, 20 \mathrm{~min})$, and a 1-ml aliquot of the solution was removed for quantitative HPLC analysis. Atrazine concentrations were measured using an L-7100 LaChrom HPLC with a Supelcosil LC-ABZ column $(25 \mathrm{~cm} \times 4.6 \mathrm{~mm}, 5 \mu \mathrm{m}$; Supelco, Bellefonte, PA, USA), a mobile phase of acetonitrile/water (60/40), and absorbance at $222 \mathrm{~nm}$.

Desorption experiments for phenanthrene and atrazine from PC1 and PC4 samples were conducted after the completion of the sorption experiments. Seventy-five percent of the supernatant was removed and replaced with fresh background solution. Then the vials were agitated under the same conditions used in the sorption experiments for an additional $3 \mathrm{~d}$. After mixing, a 1-ml aliquot of the solution was removed for quantitative HPLC analysis.

\section{Data analysis}

The Freundlich parameters $\left(K_{\mathrm{f}}\right.$ and $\left.1 / n\right)$ were calculated from the logarithmic form of the equation $q=K_{\mathrm{f}} \mathrm{C}^{1 / n}$, where 
$q$ is the total of sorbed concentration per unit weight of sorbent, $\mathrm{C}$ is the solution-phase concentration, $K_{\mathrm{f}}$ is the Freundlich distribution coefficient, and $1 / n$ is a correction factor. Isotherms were plotted $(\log q$ vs $\log \mathrm{C})$, and $\log K_{\mathrm{f}}$ and $1 / n$ were obtained from the fitting. Values of $K_{\mathrm{oc}}$ were calculated from the sorption distribution coefficient $\left(K_{\mathrm{om}}\right)$ data by normalizing to the $\mathrm{C}$ level of each type of sorbent. Molar volumes (181.9 and $181.7 \mathrm{~cm}^{3} / \mathrm{mol}$ for atrazine and phenanthrene, respectively) were calculated as the compound's molecular weight $(\mathrm{g} / \mathrm{mol})$ divided by its density $\left(\mathrm{g} / \mathrm{cm}^{3}\right)$.

\section{RESULTS AND DISCUSSION}

Plant cuticles are highly complex membranes that cover the outer surface of the aerial portion of plants. The principal components of the cuticular membrane are soluble and polymerized aliphatic lipids [20]. The polymeric lipids are divided into two major classes: cutin—a high-molecular-weight, polar, cross-linked polymer that is constructed of hydroxy-fatty acids with chain lengths of $\mathrm{C}_{16}$ and $\mathrm{C}_{18}$ that are cross-linked by ester and ether bonds and cutan - a nonsaponifiable polymethylene polymer. The function of the cuticle in foliar uptake and as a barrier against the penetration of agrochemicals and pathogens into the tissue has been the subject of several reports [21-23]. However, very little is known about the function of plant cuticular fractions as sorbents for agrochemicals and other contaminants in soils.

\section{Sorbent characterization}

The amount of external lipids, which were removed by Soxhlet extraction, was $4 \%$ by weight, whereas the fraction removed by saponification (cutin) was the major part of the cuticle, corresponding to $58 \%$ by weight (Table 1 ). A smaller loss of the total mass $(29 \%)$ occurred when the nonsaponifiable residue $(\mathrm{PC} 3)$ was acid-hydrolyzed. The final residue (nonsaponifiable nonhydrolyzable; PC4) corresponded to less than $10 \%$ of the total cuticle mass.

The FTIR spectra (Fig. 1) of the bulk cuticle and dewaxed cuticle (PC1 and PC2, respectively) were similar to spectra obtained for the cuticles of Clivia miniata and lime leaves $[24,25]$. The bands at 2,930, 2,850, 1,463, 1,370, and 1,318 $\mathrm{cm}^{-1}$ are assigned mainly to $\mathrm{CH}_{2}$ units in cutan and cutin polymers. The peaks at 1,735 and $1,165 \mathrm{~cm}^{-1}$ are assigned to $\mathrm{C}=\mathrm{O}$ and $\mathrm{C}-\mathrm{O}$ stretching vibrations of ester bonds, respectively. The peaks at $1,247,1,105,1,063$, and $1,030 \mathrm{~cm}^{-1}$ are assigned to $\mathrm{C}-\mathrm{O}$ stretching of polysaccharides.

During the saponification treatment, ester bonds were broken and the corresponding hydroxy-fatty acids removed. The depolymerization treatment resulted in a residue containing mainly the cuticular polysaccharides (the FTIR spectrum was dominated by a broad peak in $\left.1,100-1,000 \mathrm{~cm}^{-1}\right)$. The PC3 sample exhibited a significant increase in $\mathrm{O} / \mathrm{C}$ ratio (Table 1), suggesting the relative enrichment of polar functional groups (polysaccharides). When the PC3 sample was further hydrolyzed, the polysaccharides were removed, and the resultant FTIR spectrum (PC4) was dominated by peaks at 2,930 and $2,850 \mathrm{~cm}^{-1}, 1,708 \mathrm{~cm}^{-1}$ (carbonyl stretch of -COOH group), and $1,620 \mathrm{~cm}^{-1}(\mathrm{C}=\mathrm{C}$ stretching in the aromatic ring). These observations indicate that the saponification treatment did not remove all fatty acids linked by ester bonds (cutin). Villena et al. [24] suggested that partial molecular shielding by polysaccharides present in a high degree of crystallinity protects part of the cutin structure from the saponification treatment.

The CPMAS ${ }^{13} \mathrm{C}$ NMR spectra (Fig. 2) of the bulk pepper

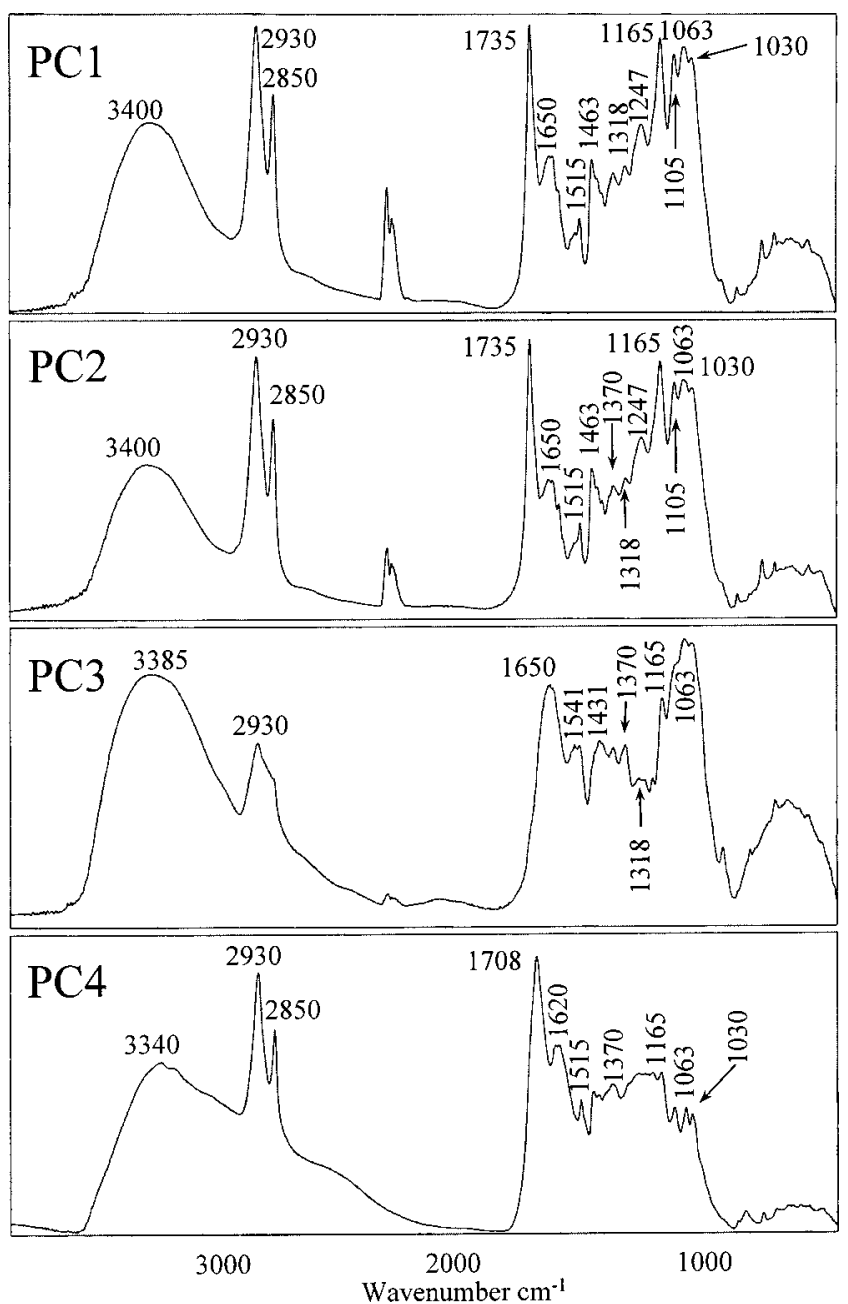

Fig. 1. Fourier transform infrared spectra of bulk pepper cuticle (PC1), dewaxed cuticle (PC2), and residues after saponification (PC3) and acid hydrolysis (PC4).

cuticle (PC1) and the dewaxed cuticle (PC2) were similar and exhibited major peaks at 26 and 29 ppm (methylene carbons); 56 ppm (methoxyl carbon); 64, 72, 83, and 105 ppm (carbohydrates); 130 ppm (C-substituted aromatic carbons); and 172 ppm (carboxyl/amide carbons). The total percentage of paraffinic carbon (0-50-ppm region) was 39 and $37.6 \%$ for PC1 and $\mathrm{PC} 2$, respectively, and the total calculated aliphaticity of the two samples was $>96 \%$. The level of aromatic carbon functionalities was 3.5 and $2.9 \%$ for $\mathrm{PC} 1$ and $\mathrm{PC} 2$, respectively. The recorded ${ }^{13} \mathrm{C}$ NMR spectra were similar to the spectra of tomato and lime cuticles $[7,25]$ but significantly different from the spectrum of cuticle isolated from spruce needles [19], which is dominated by polysaccharide signals.

The spectrum of the saponified cuticle (PC3) was dominated mainly by carbohydrate-type peaks. The total level of polysaccharides was $71 \%$ of total carbon in this sample. The significant reduction of the methylene $\mathrm{C}$ peaks from $37.6 \%$ in the PC2 sample to $14.1 \%$ in PC3 suggests that the pepper cuticle is composed mainly of the cutin polymer. After further hydrolysis of the saponified sample, the ${ }^{13} \mathrm{C}$ NMR spectrum (PC4) exhibited major peaks at 29 and $32 \mathrm{ppm}$, confirming the presence of cutan polymethylene biopolymer in the pepper cuticle. The PC4 sample contains relatively more paraffinictype structures than the bulk cuticle (42.4 vs $39.0 \%$, respectively) and is characterized by high aromatic content (total 


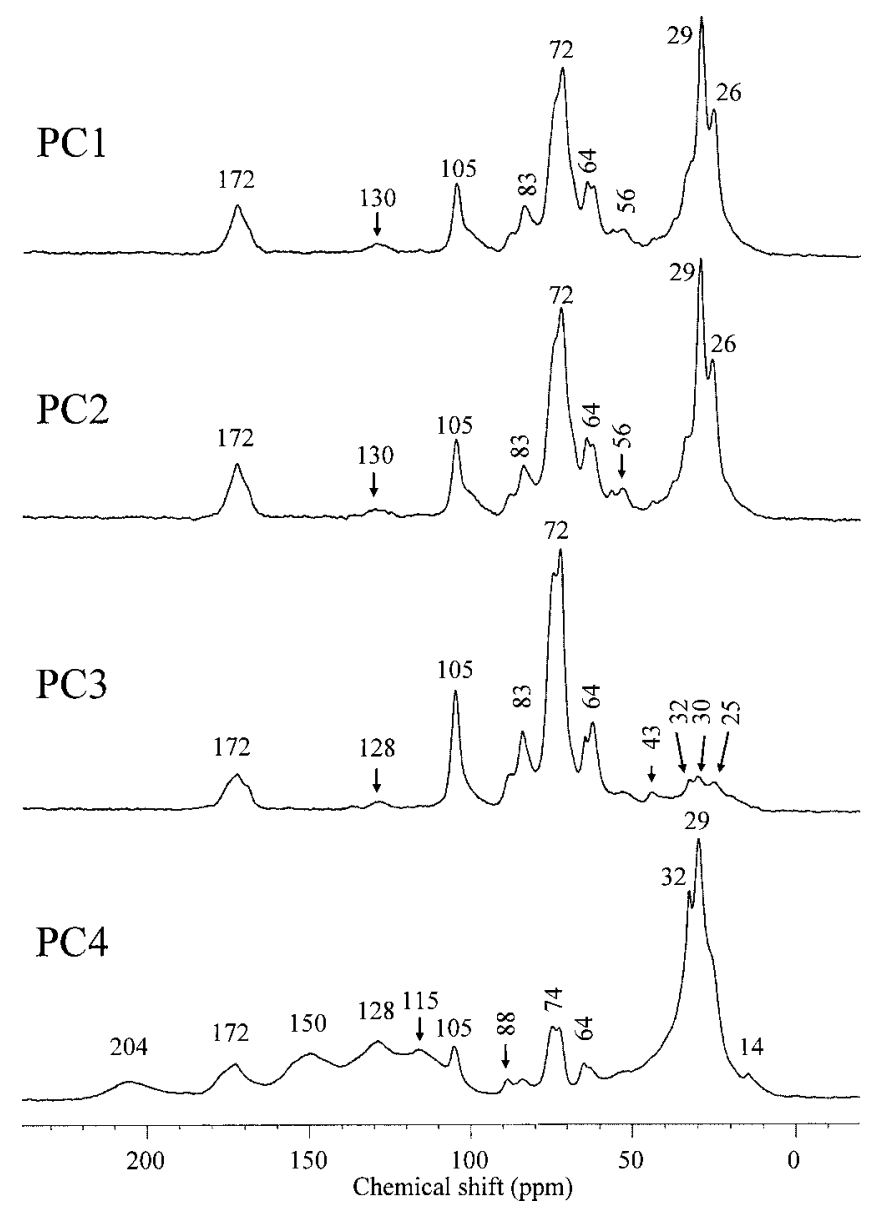

Fig. $2 .{ }^{13} \mathrm{C}$ nuclear magnetic resonance spectra of bulk pepper cuticle (PC1), dewaxed cuticle (PC2), and residues after saponification (PC3) and acid hydrolysis (PC4).

aromaticity of 30.7 vs $<4 \%$ for all other samples). Both ${ }^{13} \mathrm{C}$ NMR and FTIR spectra of the PC4 sample suggest that it consists of cutan polymer and aromatic structures that have been suggested to be lignin-like polymers [19].

\section{Phenanthrene sorption}

Sorption isotherms of phenanthrene to pepper cuticular materials are presented in Figure 3, and sorption coefficients are presented in Table 2. The highest sorption distribution coefficient $\left(K_{\mathrm{om}}\right)$ values were calculated for PC1 and PC2 (without significant differences between samples). The phenanthrene

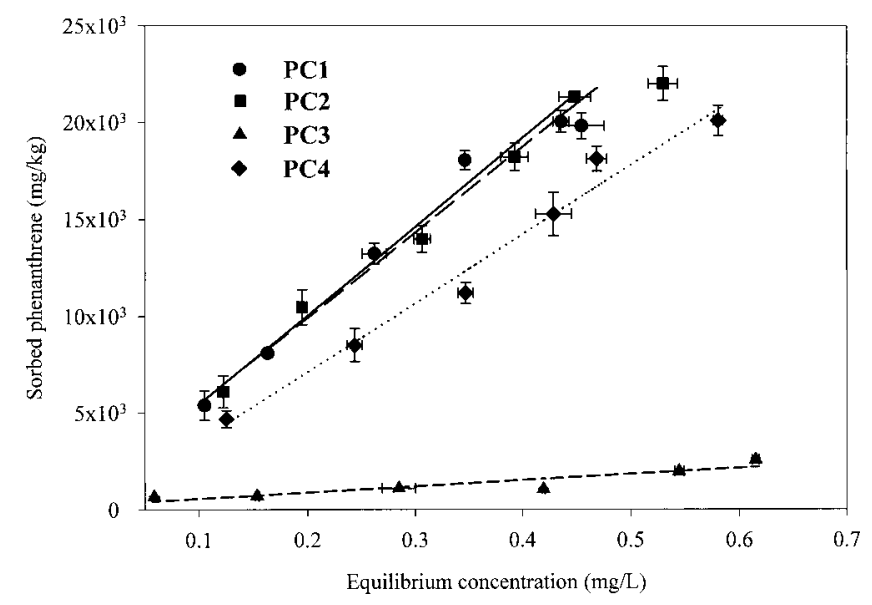

Fig. 3. Sorption isotherms of phenanthrene to pepper cuticular materials. See Figure 2 for definitions.

$K_{\text {oc }}$ values for the bulk cuticle and dewaxed cuticle (PC1 and PC2, respectively) were higher than values reported for humic substances, sediments, or soils (log $\left.K_{\text {oc }} 4.10-4.64\right)$ [3,26] and were in the lower range of values reported for wood tissue, spores, pollen, cuticle, and algae found in sedimentary rocks ( $\left.\log K_{\text {oc }} 4.8-5.6\right)$ [27]. The calculated phenanthrene $K_{\text {oc }}$ value for the cutan residue (PC4) was in the range reported for soil humic substances.

The nonlinearity of the PC1 and PC2 isotherms (Freundlich $1 / n$ values of 0.91 and 0.88 , respectively) suggests the presence of glassy paraffinic domains within the cuticle's structure. The ${ }^{13} \mathrm{C}$ NMR data suggest that the sorption coefficient of phenanthrene to PC1 and PC2 is higher than PC4 because the latter sample is composed of both crystalline and amorphous paraffinic domains (peaks at 32 and 29 ppm, respectively) [28]. On the other hand, PC1 and PC2 NMR spectra are dominated by an amorphous paraffinic domain (peak at $29 \mathrm{ppm}$ ) by which HOCs are most likely to be sorbed. The removal of external waxy materials resulted in a slight decrease in the $K_{\text {oc }}$ value by less than $4 \%$. This suggests a relatively small contribution of the external lipids of the cuticle to the overall sorption capability, similar to their proportion in the cuticle (Table 1). The significantly lower sorption obtained by PC3 is suggested to be due to the large contents of pectin polysaccharides in the sample. Removal of these polysaccharides resulted in a significant increase in $K_{\mathrm{oc}}$ value (PC4 sample).

Sorption studies with HOCs, particularly PAHs, have suggested that preferred interactions occur between them and the

Table 2. Phenanthrene and atrazine sorption coefficients and Freundlich model parameters

\begin{tabular}{|c|c|c|c|c|c|c|c|}
\hline & & $\begin{array}{c}K_{\mathrm{om}} \\
(\mathrm{ml} / \mathrm{g})\end{array}$ & Linear $r^{2}$ & $\begin{array}{c}K_{\mathrm{oc}} \\
(\mathrm{ml} / \mathrm{g})\end{array}$ & $\log K_{\mathrm{oc}}$ & $\begin{array}{c}K_{\mathrm{f}} \\
(\mathrm{mg} / \mathrm{kg}) / \\
(\mathrm{mg} / \mathrm{L})\end{array}$ & $1 / n$ \\
\hline \multicolumn{8}{|l|}{ Phenanthrene sorption sample } \\
\hline Bulk cuticle & $(\mathrm{PC} 1)$ & 45,839 & 0.97 & 77,310 & 4.88 & 43.450 & 0.918 \\
\hline Dewaxed cuticle & (PC2) & 44,116 & 0.96 & 74,610 & 4.87 & 41,380 & 0.889 \\
\hline Nonsaponifiable residue & (PC3) & 3,185 & 0.83 & 7,440 & 3.87 & 3,640 & 0.905 \\
\hline Nonhydrolyzable residue & (PC4) & 35,646 & 0.95 & 57,580 & 4.76 & 34,550 & 0.976 \\
\hline \multicolumn{8}{|l|}{ Atrazine sorption sample } \\
\hline Bulk cuticle & $(\mathrm{PC} 1)$ & 117.7 & 0.99 & 199.1 & 2.29 & 120.81 & 1.014 \\
\hline Dewaxed cuticle & (PC2) & 1353.0 & 0.99 & 228.1 & 2.35 & 137.37 & 0.983 \\
\hline Nonsaponifiable residue & (PC3) & 18.8 & 0.96 & 44.1 & 1.64 & 0.21 & 0.758 \\
\hline Nonhydrolyzable residue & (PC4) & 398.6 & 0.99 & 644.0 & 2.80 & 505.82 & 0.892 \\
\hline
\end{tabular}


aromatic moieties of the sorbent. This hypothesis is supported by a large number of observations $[1,4,5]$. However, in this study significant sorption of phenanthrene was observed by pepper cuticular matter, which is characterized as highly aliphatic. It is worth noting that both PC1 and PC2 samples exhibited aromaticity levels of $<4 \%$, but $K_{\mathrm{oc}}$ and $K_{\mathrm{f}}$ values higher than peat and humic substances, with aromaticity levels of $>20 \%[3,4]$. Moreover, the PC4 sample (cutan/lignin-like residue) exhibited a much higher level of aromatic carbon functionalities (aromaticity of $30 \%$ ) but a lower $K_{\mathrm{oc}}$ value than the PC1 or PC2 sample. Therefore, sorption of HOCs is shown to not be solely ruled by aromatic moieties of organic sorbents: Cutin, an aliphatic-rich SOM precursor, has the capability to sorb significant amounts of phenanthrene and probably other PAHs as well. These data are consistent with previous observations [7-9] showing high sorption affinity of PAHs to highly aliphatic natural and synthetic sorbents.

Another important issue regarding the sorptive potential is the structural composition of the plant cuticular material's components, which can be considered as homogeneous or separate partition media. Recently, Georgi and Kopinke [29] presented results of sorption experiments with various HOCs and dissolved humic substances using a modified Flory-Huggins concept. The basic parameter in this concept is the solubility parameter $\delta\left(\left[\mathrm{cal} / \mathrm{cm}^{3}\right]^{0.5}\right)$ of solutes and sorbents, which is a rough measure of their polarity. According to Equation 1, the $\delta_{\text {om }}$ value of the sorbent can be calculated from tabulated properties of the solute $i$ and its measured sorption coefficient $K_{\mathrm{om}, i}$ :

$\delta_{\mathrm{om}}=\delta_{i} \pm \sqrt{\left(\delta_{i}-\delta_{\mathrm{octanol}}\right)^{2}+\frac{\mathrm{RT}}{\mathrm{V}_{i}} \cdot\left(\ln K_{\mathrm{ow}, i}-\ln K_{\mathrm{om}, i}-\ln \rho_{\mathrm{om}}\right)}$

In this study, Equation 1 was applied to an interpretation of the sorption of phenanthrene $\left(\log K_{\mathrm{ow}}=4.46, \delta_{\mathrm{i}}=9.8[\mathrm{cal} /\right.$ $\left.\left.\mathrm{cm}^{3}\right]^{0.5}, \mathrm{~V}_{i}=181.7 \mathrm{~cm}^{3} / \mathrm{mol}, \delta_{\text {octanol }}=10.3\left[\mathrm{cal} / \mathrm{cm}^{3}\right]^{0.5}\right)$ to the various sorbents PC1, PC2, PC3, and PC4 ( $\rho_{\text {om }}=1.23,1.15$, 1.02 , and $1.11 \mathrm{~g} / \mathrm{cm}^{3}$, respectively). The sorption coefficients of PC1 $\left(\log K_{\text {om }}=4.66\right)$, PC2 $\left(\log K_{\text {om }}=4.64\right)$, and PC4 $(\log$ $\left.K_{\text {om }}=4.55\right)$ are slightly higher than the $\log K_{\text {ow }}$ of phenanthrene. Therefore, in the framework of the Flory-Huggins concept, these sorbents have $\delta$ values very close to that of phenanthrene itself $\left(9.8\left[\mathrm{cal} / \mathrm{cm}^{3}\right]^{0.5}\right)$. Moreover, the nonsaponifiable nonhydrolyzed cuticle fraction PC4 is considered to consist of cutan/lignin-like polymers. This is consistent with the known solubility parameter of lignin $\left(10.5\left[\mathrm{cal} / \mathrm{cm}^{3}\right]^{0.5}\right)$ as the slightly more polar component of PC4.

The sorption of phenanthrene to PC3 is significantly lower $\left(\log K_{\mathrm{om}}=3.50\right)$. It corresponds to a calculated $\delta_{\mathrm{PC} 3}$ value of $12.51\left(\mathrm{cal} / \mathrm{cm}^{3}\right)^{0.5}$. A higher $\delta$ value means a higher polarity of this sorbent. This is consistent with the high content in PC3 of a hydrolyzable, most likely pectin-like fraction. Since PC3 is composed of PC4 and the pectin-like fraction (24 and 76 wt \%; Table 1), it can be considered a chemical or physical mixture depending on the degree of blending of the two fractions on the microscale. If this blending is more or less complete on the atomic scale, the value of PC3 can be calculated as the weighted mean of its two components: $\delta_{\mathrm{PC} 3}=0.24 \cdot \delta_{\mathrm{PC} 4}$ $+0.76 \cdot \delta_{\text {pectin }}$. With the approximation $\delta_{\text {pectin }} \geq \delta_{\text {cellulose }} \approx 15.7$ $\left(\mathrm{cal} / \mathrm{cm}^{3}\right)^{0.5}$, it follows that $\delta_{\mathrm{PC} 3} \geq 14.3\left(\mathrm{cal} / \mathrm{cm}^{3}\right)^{0.5}$, which is significantly higher than the experimental value. The phenanthrene sorption coefficient of a partition medium having this $\delta$ value would be $\log K_{\mathrm{PC} 3} \leq 2.6$, compared with an experi-

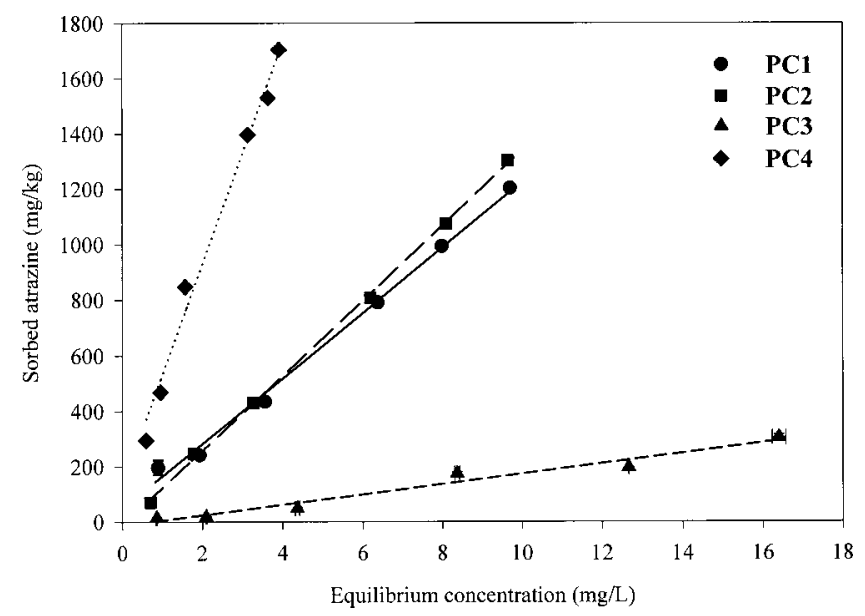

Fig. 4. Sorption isotherms of atrazine to pepper cuticular materials. See Figure 2 for definitions.

mental value of 3.5. This indicates that the assumption of a true chemical mixture is not applicable to PC3.

Alternatively, if PC3 is considered a physical mixture of two components that do not penetrate each other on the atomic scale, its sorption properties may be best described by independent partition compartments according to the relative level of each component $\left(K_{\mathrm{PC} 3}=0.24 \cdot K_{\mathrm{PC} 4}+0.76 \cdot K_{\text {pectin }}\right)$. It follows that $K_{\mathrm{PC} 3}=0.24 \cdot 35,646+0.76 \cdot 951$ (phenanthrene $K_{\text {om }}$ value for cellulose [9]) $=9,277$. This value is higher by a factor of 2.9 than the measured sorption coefficient of $K_{\mathrm{PC} 3}=3,185$ (Table 2). Therefore, the assumption of PC4 being a completely separate partition compartment in the PC3 material overestimates the sorption potential of the mixture. This indicates that PC3 can best be considered an intermediate between a physical and chemical mixture of polymeric materials, a highly polar (pectin-like) fraction, and a nonpolar (cutan/lignin-like) fraction. The second dominates the sorption potential of the mixture, but the decreasing effect of the polar component is significant.

The same procedure was applied to characterize the extent of blending of PC3 in PC2. Assuming two separate partition compartments (physical mixture), the saponified cutin fraction would contribute to the sorption potential of PC2 according to its relative level in the sample (Table 1 ), $K_{\mathrm{PC} 2}=61 \% \cdot K_{\text {cutin }}$ $+39 \% \cdot K_{\mathrm{PC} 3}$. This calculation would result in a very high sorption coefficient of $K_{\text {cutin }}(70,300), 2.4$ times higher than the $K_{\text {ow }}$ of phenanthrene, which is not very likely. Assuming PC2 as a complete chemical mixture of components according to $\delta_{\mathrm{PC} 2}$ $=61 \% \cdot \delta_{\text {cutin }}+39 \% \cdot \delta_{\mathrm{PC} 3}\left(\right.$ with $\delta_{\mathrm{PC} 2} \approx 9.8$ and $\left.\delta_{\mathrm{PC} 3}=12.51\right)$ leads to $\delta_{\text {cutin }}$ value of $\approx 8.1\left(\mathrm{cal} / \mathrm{cm}^{3}\right)^{0.5}$. This value is similar to that of polyethylene $\left(\delta_{\mathrm{PE}} \approx 8.0\left[\mathrm{cal} / \mathrm{cm}^{3}\right]^{0.5}\right)$. Thus, the conclusion for the extent of mixing of the constituents in the sorbent PC2 (cutin and PC3) is a chemical blending on the molecular scale.

\section{Atrazine sorption}

In agreement with phenanthrene sorption behavior, the sorption isotherms of atrazine by PC1 and PC2 were similar (Fig. 4 ), and the isotherm of atrazine to PC3 exhibited the lowest $K_{\text {om }}$ (Table 2). However, the sorption isotherm of atrazine to PC4 exhibited the sharpest slope, resulting in a significantly higher $K_{\text {om }}$ value $(398 \mathrm{~L} / \mathrm{kg})$ than all other sorbents. The calculated atrazine $K_{\text {om }}$ values for PC1 and PC2 were similar to those reported for tomato cuticle and dewaxed cuticle [30]. 
Removal of the cuticular waxes resulted in a $15 \%$ increase in the atrazine $K_{\mathrm{oc}}$ value and a slight decrease in the phenanthrene $K_{\mathrm{oc}}$ value. These data suggest poor sorption contribution of the surface waxes of the cuticle to overall sorption, probably because of their crystalline nature. The calculated atrazine $K_{\mathrm{oc}}$ value was significantly increased when polysaccharide was removed from the nonsaponifiable residue (PC3). In accordance with the phenanthrene sorption data, these data indicate a low affinity of the cuticular polysaccharides (pectin) to sorption of HOCs and possible structural shielding of the cutan residue (PC4). The recorded atrazine $K_{\mathrm{oc}}$ and $K_{\mathrm{f}}$ values for PC1 and $\mathrm{PC} 2$ were in the range of values reported for humic acids [31,32] and soils [33]. However, both atrazine $K_{\text {oc }}$ and $K_{\mathrm{f}}$ values for PC4 were much higher than those reported in the literature.

Charge transfer between atrazine and quinonic structures of humic materials has been suggested as a possible sorption mechanism [32,34,35]. Therefore, a high level of aromatic moieties in the organic sorbent would provide a large amount of electron-poor sites, which are likely to be active sorption sites for electron-rich sorbate molecules such as atrazine. In this study, the sorption mechanism cannot be explained by such interactions of atrazine and aromatic moieties of the sorbents as very recently presented by Kulikova and Perminova [36]. The bulk and dewaxed cuticles were characterized by very low aromatic level $(<4 \%)$ as compared to the aromaticity of humic substances and SOM but exhibited sorption coefficients in the same range. A similar trend was reported by Piccolo et al. [32], who observed high atrazine sorption to the acetone fraction of humic substances, the fraction showing the lowest aromatic contents of all the extracted fractions.

Xing et al. [31] suggested a dual-mode mechanism for atrazine sorption (partitioning and specific sorption) to SOM. Since both PC1 and PC2 samples consisted of a cutin polyesterlike biopolymer, it is suggested that sorption occurs by weak H-bonding (between the solute and the carboxylic and hydroxyl groups of the cutin), partitioning, and a hole-filling mechanism in the flexible long-chain structures of the cutin [31,32].

To evaluate whether the plant cuticular materials are capable of interacting specifically or nonspecifically with solutes, we applied the approach presented by Graber and Borisover [37] for studying sorbent-sorbate interactions by normalizing sorption to an inert solvent ( $n$-hexane). Atrazine and phenanthrene have similar molar volumes, but they are significantly different in their ability to interact with a sorbent. Atrazine can form $\mathrm{H}$ bonds and charge-transfer interactions (it is capable of specific interactions) and nonspecific interactions with the sorbent, whereas phenanthrene has no active $\mathrm{H}$ atoms to form $\mathrm{H}$ bonds and therefore can interact only nonspecifically with the sorbent. Sorption isotherms of atrazine by PC1 and PC4 were normalized to the infinitely dilute state in $n$-hexane (161 $\mathrm{mg} / \mathrm{L}$ and $44.6 \mathrm{~g} / \mathrm{L}$ for atrazine and phenanthrene, respectively) [37,38]. Since atrazine and phenanthrene have similar molar volumes, their $n$-hexane-normalized isotherms can be compared.

The slopes of the $n$-hexane-normalized isotherms of atrazine are clearly much greater than those of phenanthrene to PC1 and PC4 (Fig. 5). The larger sorption of atrazine is probably due to specific interactions (H-bonding) of the atrazine molecules with $\mathrm{H}$-acceptor sites (carboxylic groups) in the cuticle. These interactions are less significant when atrazine is sorbed from an aqueous solution (Fig. 4) as a result of atrazine-water interactions. Another interesting observation is

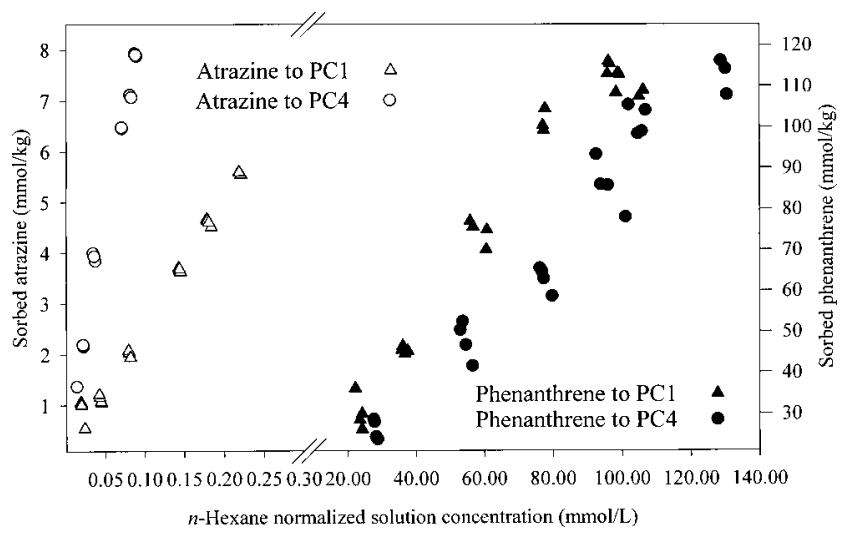

Fig. 5. n-Hexane-normalized sorption isotherms of atrazine (open symbols) and phenanthrene (filled symbols) to bulk pepper cuticle (PC1; triangles) and the nonsaponifiable nonhydrolyzable cuticle residue (PC4; circles). See Figure 2 for definitions.

that the difference between the $n$-hexane-normalized isotherm for atrazine and that for phenanthrene is much greater for PC4 than for PC1 (Fig. 5). The isotherm slope ratio (slope of atrazine divided by the slope of phenanthrene) for PC1 is 21 , whereas the ratio is 91 for PC4. Although both samples exhibited similar O content (31\%), it is suggested that the PC4 residue provides more sites for specific interactions with atrazine than the bulk cuticle (PC1). Such sites might be carboxylic groups, which can form proton-transfer complexes with atrazine. This hypothesis is supported by the FTIR spectrum of PC4, which is dominated by a large peak of carboxylic groups at $1,708 \mathrm{~cm}^{-1}$ (Fig. 1). In addition, the NMR spectrum of this sample exhibited a keto peak at $204 \mathrm{ppm}$, which is absent in all other samples (Fig. 2). These keto functional groups can serve as $\mathrm{H}$-acceptor sites for bonding atrazine. It is therefore suggested that the PC4 structural composition is more favorable for specific interactions with atrazine than PC1 or PC2.

\section{Desorption}

Desorption data and mainly desorption hysteresis can provide further insight into the sorptive mechanism and structural composition of the sorbent. Desorption parameters for phenanthrene were 44,225 and $36,400 \mathrm{~L} / \mathrm{kg}$ for PC1 and PC4, respectively; for atrazine they were 113.7 and $400.2 \mathrm{~L} / \mathrm{kg}$ for PC1 and PC4, respectively. No significant hysteresis was observed in the desorption isotherms, and the desorption coefficients were similar to the recorded sorption coefficients (Table 2). In our study, the absence of sorption hysteresis suggests that partitioning is the main sorption mechanism for phenanthrene and that flexible hydrophobic domains are the major sorptive sites within the cuticular materials. The Freundlich $1 / n$ value (0.91) calculated for the sorption isotherm of phenanthrene to PC1 suggests a contribution to the sorption by the glassy aliphatic domain of the cuticle. However, these domains were expected to result in desorption hysteresis, which was not observed. Therefore, it is speculated that specific hydrophobic sites are involved in the sorption process of phenanthrene, and they are probably the cause of the sorption nonlinearity.

\section{CONCLUSIONS}

This study demonstrates the markedly high sorption capacity of pepper cuticle for phenanthrene and atrazine. Both 
cutin (the main polymer of the pepper cuticle; $58 \%$ by weight) and cutan biopolymers exhibit high sorption capability, even though both sorbents are highly aliphatic in nature. However, the aliphatic structures, which probably provide hydrophobic sorption domains, are not the only ones important for sorption of relatively polar compounds (atrazine). The high $n$-hexanenormalized sorption of atrazine suggests specific sorption sites that could provide opportunities for H-bonding. The solubility parameters data provide insight into the nature of mixing of the different constituents of the pepper cuticle. The PC3 sample is considered as intermediate stage between being physical and chemical mixture of pectin and cutan/lignin-like fractions, whereas the PC2 sample is a chemical mixture of cutin and PC3.

Since cutin and cutan have been identified as part of SOM and humic substances $[14,15,18]$, it is suggested that retention of HOCs in soils is also controlled by these aliphatic domains and not only by the aromatic-rich fractions of SOM.

Acknowledgement-The author thanks P.G. Hatcher (Ohio State University) for performing the solid-state ${ }^{13} \mathrm{C}$ NMR measurements. The author also thanks F.-D. Kopinke (UFZ-Center for Environmental Research, Leipzig, Germany) for helpful suggestions.

\section{REFERENCES}

1. Chin YP, Aiken GR, Danielsen KM. 1997. Binding of pyrene to aquatic and commercial humic substances: The role of molecular weight and aromaticity. Environ Sci Technol 31:1630-1635.

2. Luthy RG, Aiken GR, Brusseau ML, Cunningham SD, Gschwend PM, Pignatello JJ, Reinhard M, Traina SJ, Weber WJ Jr, Westall JC. 1997. Sequestration of hydrophobic organic contaminants by geosorbents. Environ Sci Technol 31:3341-3347.

3. Chiou CT, McGroddy SE, Kile DE. 1998. Partition characteristics of polycyclic aromatic hydrocarbons on soils and sediments. Environ Sci Technol 32:264-269.

4. Johnson MD, Huang W, Weber WJ Jr. 2001. A distributed reactivity model for sorption by soils and sediments. 13. Simulated diagenesis of natural sediment organic matter and its impact on sorption/desorption equilibria. Environ Sci Technol 35:16801687.

5. Perminova IV, Grechishcheva NY, Petrosyan VS. 1999. Relationships between structure and binding affinity of humic substances for polycyclic aromatic hydrocarbons: Relevance of molecular descriptors. Environ Sci Technol 33:3781-3787.

6. Ahmad R, Kookana RS, Alston AM, Skjemstad JO. 2001. The nature of soil organic matter affects sorption of pesticides. 1 . Relationships with carbon chemistry as determined by $13 \mathrm{C}$ CPMAS NMR spectroscopy. Environ Sci Technol 35:878-884.

7. Chefetz B, Deshmukh AP, Hatcher PG, Guthrie EA. 2000. Pyrene sorption by natural organic matter. Environ Sci Technol 34:29252930.

8. Kopinke FD, Georgi A, Mackenzie K. 2001. Sorption of pyrene to dissolved humic substances and related model polymers. 1. Structure-property correlation. Environ Sci Technol 35:25362542.

9. Salloum MJ, Chefetz B, Hatcher PG. 2002. Phenanthrene sorption by aliphatic-rich natural organic matter. Environ Sci Technol 36: 1953-1958.

10. Kogel-Knabner I. 1997. 13C and 15N NMR spectroscopy as a tool in soil organic matter studies. Geoderma 80:243-270.

11. Zech W, Senesi N, Guggenberger G, Kaiser K, Lehmann J, Miano TM, Miltner A, Schroth G. 1997. Factors controlling humification and mineralization of soil organic matter in the tropics. Geoderma 79:117-161.

12. Almendros G, Guadalix ME, Gonzalez-Vila FJ, Martin F. 1996. Preservation of aliphatic macromolecules in soil humins. Organic Geochemistry 24:651-659.

13. Lichtfouse E, Bardoux G, Mariotti A, Balesdent J, Ballentine DC, Macko SA. 1997. Molecular, 13C and 14C evidence for the al- lochtonous and ancient origin of C16-C18 n-alkanes in modern soils. Geochim Cosmochim Acta 61:1891-1898.

14. Nierop KGJ. 1998. Origin of aliphatic compounds in a forest soil. Organic Geochemistry 29:1009-1016.

15. Kogel-Knabner I, Hatcher PG, Tegelaar EW, De Leeuw JW. 1992. Aliphatic components of forest soil organic matter as determined by solid-state 13C NMR and analytical pyrolysis. Sci Total Environ 113:89-106.

16. Augris N, Balesdent J, Mariotti A, Derenne S, Largeau C. 1998. Structure and origin of insoluble and non-hydrolyzable, aliphatic organic matter in a forest soil. Organic Geochemistry 28:119124.

17. Rice JA. 2001. Humin. Soil Sci 166:848-857.

18. Chefetz B, Salloum MJ, Deshmukh AP, Hatcher PG. 2002. Structural components of humic acids as determined by chemical modifications and 13C NMR, pyrolysis- and thermochemolysis-GC/ MS. Soil Sci Soc Am J 66:1159-1172.

19. Kogel-Knabner I, de Leeuw JW, Tegelaar EW, Hatcher PG, Kerp H. 1994. A lignin-like polymer in the cuticle of spruce needles: Implications for the humification of spruce litter. Organic Geochemistry 21:1219-1228.

20. Kolattukudy PE. 2001. Polyesters in higher plants. Adv Biochem Eng Biotechnol 71:1-49.

21. Kirkwood RC. 1999. Recent developments in our understanding of the plant cuticle as a barrier to the foliar uptake of pesticides. Pestic Sci 55:69-77.

22. Price CE. 1982. A review of the factors influencing the penetration of pesticides through plant leaves. In DF Cutler, Alvin KL, Price CE, eds, The Plant Cuticle, Vol 10. Academic, London, UK, pp 237-253.

23. Chamel A. 1986. Foliar absorption of herbicides: Study of the cuticular penetration using isolated cuticles. Physiol Veg 24:491507.

24. Villena JF, Dominguez E, Heredia A. 2000. Monitoring biopolymers present in plant cuticles by FT-IR spectroscopy. J Plant Physiol 156:419-422.

25. Pacchiano RA Jr, Sohn W, Chlanda VL, Garbow JR, Stark RE. 1993. Isolation and spectral characterization of plant cuticle polyesters. J Agric Food Chem 41:78-83.

26. Huang W, Young TM, Schlautman MA, Yu H, Weber WJ Jr. 1997. A distributed reactivity model for sorption by soils and sediments. 9. General isotherm nonlinearity and applicability of the dual reactive domain model. Environ Sci Technol 31:1703-1710.

27. Kleineidam S, Ruegner H, Ligouis B, Grathwohl P. 1999. Organic matter facies and equilibrium sorption of phenanthrene. Environ Sci Technol 33:1637-1644.

28. Hu W, Mao J, Xing B, Schmidt-Rohr K. 2000. Poly(methylene) crystallites in humic substances detected by nuclear magnetic resonance. Environ Sci Technol 34:530-534.

29. Georgi A, Kopinke FD. 2002. Validation of a modified FloryHuggins concept for description of HOC sorption on dissolved humic substances. Environ Toxicol Chem 21:1766-1774.

30. Chamel A, Vitton N. 1996. Sorption and diffusion of 14C-atrazine through isolated plant cuticles. Chemosphere 33:995-1003.

31. Xing B, Pignatello JJ, Gigliotti B. 1996. Competitive sorption between atrazine and other organic compounds in soils and model sorbents. Environ Sci Technol 30:2432-2440.

32. Piccolo A, Conte P, Scheunert I, Paci M. 1998. Atrazine interactions with soil humic substances of different molecular structure. J Environ Qual 27:1324-1333.

33. Moreau C, Mouvet C. 1997. Sorption and desorption of atrazine, deethylatrazine, and hydroxyatrazine by soil and aquifer solids. J Environ Qual 26:416-424.

34. Senesi N. 1992. Binding mechanisms of pesticides to soil humic substances. Sci Total Environ 123/124:63-76.

35. Sposito G, Martin NL, Yang A. 1996. Atrazine complexation by soil humic acids. J Environ Qual 25:1203-1209.

36. Kulikova NA, Perminova IV. 2002. Binding of atrazine to humic substances from soil, peat, and coal related to their structure. Environ Sci Technol 36:3720-3724.

37. Graber ER, Borisover MD. 1998. Hydration-facilitated sorption of specifically interacting organic compounds by model soil organic matter. Environ Sci Technol 32:258-263.

38. Wefer RA, Graber ER, Borisover MD, Adar E, Nativ R, Ronen Z. 2001. Sorption of organic contaminants in a fractured chalk formation. Chemosphere 44:1121-1130. 